\title{
Design of Water Fire Extinguishing System for Protection of Metro Rolling Stock Stagnation Zones
}

\author{
Ilya Filippov ${ }^{1}$, Vladimir Yusupdzhanov ${ }^{1}$, Olga Zybina ${ }^{1}$, Ilya Klochihin ${ }^{1}$, and Ekaterina Chalovskaya ${ }^{1}$ \\ ${ }^{1}$ Peter the Great St.Petersburg Polytechnic University, Higher school of technosphere safety, RU-195251, Saint-Petersburg, Russian \\ Federation
}

\begin{abstract}
Metro rolling stock stagnation zones are quite long. This causes a number of difficulties in choosing and designing a water fire extinguishing system, as it directly affects the pressure loss in pipelines when water is supplied over such a long distance. That is why the task of this work is to design two different types of water fire extinguishing for metro dead ends and to perform hydraulic calculations, based on the results of which to choose the most suitable system for the object under study. The choice of a fire extinguishing system to ensure fire safety of dead ends of rolling stock sludge is made in the favor of the fire extinguishing system with high-pressure water spray.
\end{abstract}

\section{Introduction}

Fire extinguishing is designed for localization of ignition of the railway car within the zone of dead ends, which provides night rolling stock to prevent the spread of fire, protect structures, cable networks and equipment and to ensure safe conditions for the firefighting forces of EMERCOM of Russia and firefighters [1-7].

The purpose of the work is to develop a methodology for evaluating fire extinguishing systems in relation to various types of water fire extinguishing systems, further selecting the most suitable one for working in areas of sedimentation of rolling stock and ensuring fire protection of the object.

To achieve this goal, the following problems have to be solved:

1. Analysis of fire safety of the object;

2. Design of two different types of water fire extinguishing for the object/system being studied;

3. The hydraulic calculations of the designed fire suppression systems;

4. Selection of the most suitable fire extinguishing system for the object/system being studied based on the calculation results.

The object of research in this work is the fire protection system in the dead ends of the metro with areas of sedimentation of rolling stock. The subject of research pursued in this paper is the development of the project of the most suitable fire extinguishing system for operation in the conditions of the metro object being studied.

Metro dead ends are a complex object/system, both in terms of construction and technical issues [8-11]. In the field of fire fighting, there are a sufficient number of legal acts regulating the requirements for design, installation and operation [12]. However, objects that need to be protected from a possible fire have a striking difference from each other and have their own distinct features. That is why there exist additional conditions and features in the design, installation, commissioning and operation of such objects and it is also necessary to develop special recommendations for the installation and operation of fire extinguishing on them.

This work is important due to the need to prevent a fire in the dead ends of the underground areas of sediment rolling stock, to choose the right sprinkler system and to ensure all the necessary technical means for the exploitation of the fire-extinguishing system and effective extinguishing of a possible fire [12-15]. The results of the present study amy be interesting and useful for developers/designers of fire protection systems, specialists in the field of transport, fire and technosphere safety.

The source of fire load in dead ends is the eight-car rolling stock. According to the degree of fire hazard, the extinguishing zone belongs to the 2nd group of premises $[16,17]$. Ignition of rolling stock by burning substances and class A materials, solid substances [18] is possible. According to the [19], it is a zone of class P-IIA in which solid combustible substances are handled [19, 20]. Between the distillation tunnels and dead ends of the night sediment, it is necessary to build two-thread drencher water curtains based on drencher sprayers [17, 20, 21]. General-purpose automatic fire systems are designed in accordance with [17], and automatic fire extinguishing systems with high-pressure thin-spray water are designed in accordance with internal fire safety standards and [17].

In accordance with the group of premises for fire hazard (group 2), fire classes (A, E), clause 5.1.4 and section 5.4 of SP 5.13130 .2009 , with table 5.1, the estimated fire extinguishing area is 120 sq. m. and the 
duration of the automatic fire extinguishing system opertaion is at least 60 minutes [17]. The irrigation intensity when using a general-purpose fire extinguishing system for the protected area is assumed to be $0.180 \mathrm{l} /(\mathrm{s} \mathrm{m} 2)$. The intensity of irrigation when using automatic fire extinguishing system with thinly sprayed high-pressure water is not strictly limited [17]

\section{Methods}

\subsection{Methods of hydraulic calculation of fire extinguishing systems with high-pressure thin- spray water}

Water fire extinguishing systems use various communications. An integral part of the aggregate water fire extinguishing system are pipelines that supply the extinguishing agent (water) to the sprayers. It is in connection with this function that hydraulic calculations are necessary.

In order to confirm (clarify) the selected diameters of the pipeline and pipeline fittings, a hydraulic calculation is performed by calculating the pressure drop during the flow of water from the pumping unit to the most remote sprayers of the calculated irrigation area using the Darcy-Weisbach method. [21]

To simplify the calculation, the pipeline is divided into sections so that within each section there is no change in the parameters of the liquid flow (flow rate). The velocity of the liquid flow is determined by the formula (1).

$$
V=(4 \cdot Q) /\left(\pi \cdot D_{\mathrm{i}}^{2}\right)
$$

where $\mathrm{Q}$ is the liquid flow rate, $\mathrm{m}^{3} / \mathrm{s}$

$\mathrm{D}_{\mathrm{i}}$ - inner diameter of the pipe, $\mathrm{m}$.

Pressure loss at each site consist of the pressure losses along the length of the pipe (due to wall friction), pressure losses in smooth pipe bends (with bending pipe is meant for a smooth change of flow direction along the radius not less than $2,5 \cdot D$, where $D$ is the diameter of the pipe) and the pressure drop with a sharp bend (a sharp turn of flow at $90^{\circ}$, such as a tee or elbow). Thus, the pressure drop in the section is determined by the formula (2):

$$
\Delta \rho=\Delta \rho_{\lambda}+\Delta \rho_{b}+\Delta \rho_{e},
$$

where $\Delta \rho_{\lambda}$ is the pressure loss along the length of the pipe;

$\Delta \rho_{b}$ - pressure loss during smooth bending of the pipe;

$\Delta \rho_{e}$ - pressure loss when the pipe bends sharply.

To determine the pressure loss along the length of the pipe, the Reynolds number must be calculated using the formula (3):

$$
\operatorname{Re}=(\rho \cdot V \cdot D i) / \mu
$$

where $\rho$ is the density of the liquid; $\mu$ is the dynamic viscosity of the liquid.
Depending on the Reynolds number, the fluid flow mode for this section is determined.

For laminar flow $(\mathrm{Re}<2300)$, the pressure loss along the length of the pipe is determined by the DarcyWeisbach formula (4):

$$
\Delta \rho_{\lambda} \quad=\quad \lambda_{L} \cdot\left(L \cdot V^{2}\right) /(2 \cdot D) \cdot \rho
$$

where $L$ is the length of the pipeline section;

$D$ - diameter of pipeline;

$\lambda_{L}-$ coefficient of pressure losses along the length of the;

$\rho$ is the density of the liquid.

For laminar flow, the coefficient of pressure loss for friction along the length is determined by the Poiseuille formula (5):

$$
\lambda_{L}=64 / R e
$$

For turbulent flow ( $\operatorname{Re}>2300$ ), the pressure loss along the length of the pipe is determined by the DarcyWeisbach formula (6):

$$
\Delta \rho_{\lambda=} \lambda T \cdot\left(L \cdot V^{2}\right) /(2 \cdot D) \cdot \rho
$$

where $L$ is the length of the pipeline section; $\lambda_{L}$ - coefficient of pressure loss along the length.

In a turbulent flow, the coefficient of pressure loss for friction along the length is determined from the equation (7):

$$
1 / \sqrt{ }\left(\lambda_{T}\right)=-2 \cdot \operatorname{Lg} \cdot\left[2,51 /\left(R e \cdot \sqrt{ }\left(\lambda_{T}\right)\right)+e /\left(3,72 \cdot D_{i}\right)\right]
$$

where e is the relative roughness (which in laminar flow does not affect the flow structure, but only increases the streamlined surface, and also does not affect the friction resistance);

$D_{i}$ - inner diameter of the pipe, $\mathrm{m}$.

From this equation, the coefficient $\lambda_{L}$ is determined using the iterative method.

Also, the Blasius formula (8) is often used to determine the coefficient of pressure loss for friction along the length during turbulent flow:

$$
\lambda_{L}=0,316 / \sqrt[4]{R e}
$$

However, this paper uses the derivation of the coefficient $\lambda_{L}$ from equation 7 .

The pressure loss during a smooth bend of the pipe is determined by the formula (9):

$$
\Delta \rho_{b}=\left(B \cdot \varepsilon_{b} \cdot \rho \cdot V^{2}\right) / 2
$$

where $B$ is the number of smooth bends in the selected section;

$\varepsilon_{b}$ - coefficient of pressure loss during bending.

The total pressure loss is defined as the algebraic sum of the losses in each section by the formula (10):

$$
\Delta \rho_{\Sigma}=\sum \Delta \rho_{i}
$$


The initial data for the hydraulic calculation are situational plans and a block diagram of an automatic fire extinguishing system with fine water.

The calculation section is determined from the diagram. For the first approximation, the pipe diameters are selected depending on the characteristics of the designed fire extinguishing system. In this paper, the following pipe diameters are selected:

- from pump unit to sectional valves - D38 pipe;

- looped feed pipe - D38 pipe;

- taps to sprayers - D12 pipe.

Constant coefficients required for calculation: $\rho=1000 \mathrm{~kg} / \mathrm{m}^{3} ; \mu=0,001 \mathrm{~Pa} \cdot \mathrm{s} ; \mathrm{e}=3 \cdot 10^{-5}$.

The maximum pressure drop is determined from the calculation results. Then the result obtained after calculations is added to the minimum pressure on the sprayer equal to $6 \mathrm{MPa}$. If it is necessary to reduce the output pressure, it is necessary to increase the dimensions of the valve and pipeline diameters, and then perform the hydraulic calculation again.

\subsection{Methods of hydraulic calculation of standard water fire extinguishing systems}

Further, the paper presents the main mathematical dependencies of the calculation method [17].

The following formula (11) is used to determine the estimated water flow on the dictating sprinkler located within the dictating irrigation zone):

$$
q=10 \cdot K \cdot \sqrt{ } P
$$

where $q$ is the flow rate of the extinguishing agent (in this case, water) on the dictating sprinkler, $l / s$;

$K$ is the productivity coefficient of the sprinkler, which is set depending on the technical documentation for the product, $\mathrm{l} /\left(\mathrm{s} \cdot \mathrm{MPa}^{0.5}\right)$;

$P$ - pressure on the dictating sprinkler, $M P a$.

This formula (12) is used to determine pipe diameters in a section of the pipeline network

$$
d=1000 \cdot \sqrt{ }((4 \cdot Q) / \pi \mu v)
$$

where $d$ is the diameter of the pipeline sections in the intervals between sprinklers, $\mathrm{mm}$;

$Q$ - direct flow rate of sprinklers, l / s;

$\mu$ - coefficient of discharge;

$v$ - the speed of water movement within the calculated sections of the pipeline network, $\mathrm{m} / \mathrm{s}$ (the speed must be below $10 \mathrm{~m} / \mathrm{s}$ ).

The following formula (13) is used to determine the pressure loss in a section of the pipeline network:

$$
P=(Q \cdot L)\left(100 \cdot K_{T}\right)
$$

where $Q$ is the total consumption of fire extinguishing agent (water) on the first and second sprinklers, $1 / \mathrm{s}$;

$K_{T}$ - specific characteristic of the pipeline, l/s;

$L$ is the length of the pipeline.

The pressure of the second sprinkler after the dictating one is determined by the formula (14):

$$
P_{2}=P_{1}+P_{(1-2)}
$$

The flow rate of the second sprinkler is obtained from the formula (15):

$$
q_{2}=10 \cdot K \cdot \sqrt{ }\left(P_{2}\right)
$$

The generalized characteristic of a series (branch) is calculated by the formula (16):

$$
B=Q_{2} / P
$$

For the calculation of automatic sprinkler fire extinguishing systems, the condition presented in the formula (17):

$$
Q_{n} \leq Q_{c}
$$

where $Q_{n}$ is the standard flow rate of an automatic sprinkler fire extinguishing system;

$Q_{c}$ - actual consumption of the automatic sprinkler fire extinguishing system.

To determine the number of sprinklers that can provide the actual flow rate of an automatic sprinkler fire extinguishing system $\mathrm{Q}_{c}$ with an irrigation intensity exceeding the standard (when taking into account the configuration of the selected protected area), the condition presented in the formula (18) is used:

$$
n \geq S / \Omega
$$

where $\mathrm{n}$ is the minimum number of sprinkler sprinklers that can provide the actual flow rate of an automatic sprinkler fire extinguishing system $\mathrm{Q}_{\mathrm{c}}$ with an irrigation intensity exceeding the standard;

$\mathrm{S}$ is the minimum protected irrigated area, taking into account the data presented in table 5.1 of [17];

$\Omega$ is the conditional calculated area, the protection of which is provided by one sprinkler and is determined by the following formula (2.19):

$$
\Omega=L^{2}
$$

where $\mathrm{L}$ is the set distance between sprinklers.

Due to the fact that the pressure on each Sprinter is different, and the lowest pressure is on the dictating Sprinter, it is necessary to take into account the flow rate of each Sprinter from the total amount.

To determine the total water consumption of a drencher automatic fire extinguishing system, a sequential summation of the costs of all sprinklers located in the protected area is carried out using the formula (20):

$$
Q_{d}=\sum_{n-1}^{n} q_{n}
$$

where $Q_{d}$ is the calculated flow rate of the drencher automatic fire extinguishing system, l/s;

$\mathrm{q}_{\mathrm{n}}$ - direct flow rate of the nth sprinkler, $\mathrm{l} / \mathrm{s}$;

$\mathrm{n}$ is the total number of sprinklers located in the protected area. 
The flow rate $Q_{s}$ of an automatic sprinkler fire extinguishing system with a water curtain is determined by the formula (21):

$$
Q_{s}=Q_{c}+Q_{z}
$$

where $\mathrm{Q}_{\mathrm{c}}$ is the flow rate of the automatic sprinkler fire extinguishing system;

$\mathrm{Q}_{\mathrm{z}}$ - water curtain flow rate.

If a combined fire water supply system is designed on the site (i.e. combined lines from automatic fire extinguishing systems and internal fire water), then allowed to set one group of pumps, while ensuring that group flow $\mathrm{Q}$, is equal to the summed costs for each vocopro-water, that represented in the formula (22):

$$
Q=Q s+Q i n t
$$

where $Q_{s}, Q_{i n t}$ - respectively, the flow rate of the internal fire-fighting water supply and the flow rate in the pipeline network of an automatic fire extinguishing system.

To calculate the required pressure of a fire pump, this formula is generally used (23):

$$
P_{n}=P_{h}+P_{v}+\sum P_{L}+P_{C U}+P_{D}+Z-P_{p f}=P_{r e q}-P_{f p}
$$

where $\mathrm{P}_{\mathrm{n}}$ is the required pressure on the fire pump, MPa; $\mathrm{P}_{\mathrm{h}}$ - pressure loss on the horizontal section of the $A B$ pipeline, MPa;

$\mathrm{P}_{\mathrm{v}}$ - pressure loss on the vertical section of the DB pipeline, MPa;

$\mathrm{P}_{\mathrm{L}}$ - pressure loss in local resistances, $\mathrm{MPa}$;

$\mathrm{P}_{\mathrm{CU}}$ - the local resistance in the control units (at the gates, valves and alarm valve), $\mathrm{MPa}$;

$\mathrm{P}_{\mathrm{D}}$ - pressure on the dictating sprinkler, $\mathrm{MPa}$;

$\mathrm{Z}$ - piezometric pressure (geometric height of the dictating sprinkler above the fire pump axis), $\mathrm{MPa}$; $\mathrm{Z}=\mathrm{H} / 100$;

$\mathrm{P}_{\mathrm{fp}}$ - pressure at the inlet of the fire pump, MPa;

$\mathrm{P}_{\text {req }}$ - required pressure of the fire pump, $\mathrm{MPa}$.

The following formulas (24), (25) are used to determine the pressure loss in the control units: - in the sprinkler:

$$
P_{\text {CUS }}=\xi_{C U S} \cdot \gamma \cdot Q^{2}=\left(\xi_{V S}+\xi_{\text {Sod }}\right) \cdot \gamma \cdot Q^{2}
$$

- in drencher:

$$
P_{C U D}=\xi_{C U D} \cdot \gamma \cdot Q^{2}=\left(\xi_{V D}+2 \cdot \xi_{\text {Sod }}\right) \cdot \gamma \cdot Q^{2}
$$

where $\xi_{\mathrm{CUS}}, \xi_{\mathrm{CUD}}, \xi_{\mathrm{VS}}, \xi_{\mathrm{VD}}, \xi_{\mathrm{sod}}$ - pressure loss coefficients, respectively, in the sprinkler and drencher control unit, in the sprinkler and drencher signal valve and in the shut-off device (accepted according to the technical documentation for the control unit as a whole or for each signal valve, gate or gate valve individually); $\gamma$ is the density of water, $\mathrm{kg} / \mathrm{m}^{3}$;

Q-estimated flow rate of water passing through the control unit, $\mathrm{m}^{3} / \mathrm{h}$.

In approximate calculations, local resistances are assumed to be equal to $20 \%$ of the resistance of the entire pipeline network, taking into account losses in control unit.

Unless otherwise specified in the technical specifications, the calculations are carried out so that the pressure at the control units does not exceed $1 \mathrm{MPa}$.

The duration of the fire extinguishing agent supply (in this case, water) is accepted, taking into account the selected group of the protection object according to table 5.1, Appendix B of [17].

After a proper study of the calculation methods used in the work, it is necessary to give the methodology itself, according to which the choice of a particular fire extinguishing system was made based on the results of calculations.

\section{Results}

\subsection{Hydraulic calculation of the fire extinguishing system with high-pressure water spray}

The maximum pressure drop is determined from the results obtained during the calculation. Then the result obtained after calculations is added to the minimum pressure on the sprayer equal to $6 \mathrm{MPa}$. If it is necessary to reduce the output pressure, increase the size of the valve and pipeline diameters, and then perform the hydraulic calculation again. The calculation results are shown in table 1.

Table 1. Results of calculation of the fire extinguishing system with high-pressure water spray

\begin{tabular}{|l|c|c|c|c|c|c|c|c|}
\hline № & $\begin{array}{c}\mathrm{Q}, \\
\text { l/min }\end{array}$ & L, m & E & B & $\begin{array}{c}\mathrm{V}, \\
\mathrm{m} / \mathrm{s}\end{array}$ & Re & $\begin{array}{c}\mathrm{dPi} \\
\mathrm{kg} / \mathrm{sm} 2\end{array}$ & $\begin{array}{c}\mathrm{dP}, \\
\mathrm{kg} / \mathrm{sm} 2\end{array}$ \\
\hline 1 & 34,2 & 0,5 & 2 & 2 & 8,96 & 80679 & 1,56 & 1,56 \\
\hline 2 & 34,2 & 9 & 2 & 2 & 0,71 & 22691 & 0,03 & 1,59 \\
\hline 3 & 68,4 & 9 & 2 & 2 & 1,42 & 45382 & 0,09 & 1,68 \\
\hline 4 & 85,50 & 380 & 15 & 15 & 1,77 & 56728 & 4,73 & 6,41 \\
\hline 5 & 171 & 5 & 8 & 8 & 3,55 & 113455 & 0,79 & 7,20 \\
\hline 6 & 342 & 5 & 8 & 8 & 7,09 & 226911 & 3,12 & 10,33 \\
\hline 7 & 171 & 3 & 8 & 8 & 3,55 & 113455 & 0,70 & 11,03 \\
\hline 8 & 128,25 & 425 & 45 & 45 & 2,66 & 85092 & 12,50 & 23,54 \\
\hline 9 & 256,5 & 3 & 6 & 6 & 5,32 & 170183 & 1,25 & 24,79 \\
\hline
\end{tabular}

The following designations are used in the table: - № - number of the pipeline section;

- $\mathrm{L}$ - length of the pipe section;

- Q-consumption;

- $\mathrm{E}$ - the number of sharp bends of the pipe in the section where the flow turns 900

- B - number of smooth bends on the section;

- $\Delta \mathrm{p}$ - pressure loss on the pipe section;

- $\sum \Delta \mathrm{p}$ - total head loss.

The pipe diameter of 1 section of the pipeline is 12 $\mathrm{mm}$, the pipe diameter of 2-9 sections of the pipeline is $38 \mathrm{~mm}$. The wall thickness of the pipe of 1 section of the pipeline is $1.5 \mathrm{~mm}$, the wall Thickness of the pipes of 29 sections of the pipeline is $3 \mathrm{~mm}$. 
Based on the calculation results, it can be concluded that at the maximum flow rate of $513.0 \mathrm{l} / \mathrm{min}$ (simultaneous operation of 10 sprinklers on an estimated area of $120 \mathrm{~m} 2-342.0 \mathrm{l} / \mathrm{min}$ and a drainpipe curtain $171.0 \mathrm{l} / \mathrm{min}$ ), the system performance is not impaired. The minimum pressure on the sprayers does not fall below $60 \mathrm{Bar}$ (6.0 MPa).

To ensure normal operation of the system, it is necessary to ensure a maximum pressure drop of no more than 25 Bar (2.5 MPa), since the guaranteed pressure at the outlet of the pump unit is 85 Bar (8.5 $\mathrm{MPa}$ ), and the minimum operating pressure at the sprayers is $60 \mathrm{Bar}(6.0 \mathrm{MPa})$.

As follows from the calculations, the total pressure drop and pipe velocity in all cases do not exceed the permissible values. Therefore, the selected pipe diameters meet the system requirement.

The pump unit is selected for a maximum design flow rate of $513.0 \mathrm{l} / \mathrm{min}$ and a $10 \%$ capacity margin according to the manufacturer's requirements. Based on the fact that the capacity of one pump unit is $100 \mathrm{l} / \mathrm{min}$, the project adopted a pumping unit consisting of 7 pump units ( 6 working and 1 backup).

\subsection{Hydraulic calculation of standard water fire extinguishing systems}

Operation of sprinklers in dead ends of night sedimentation of rolling stock on 3 track (this section is selected as potentially dangerous due to the large number of sprayers and significant distance from the pumping station). Extinguishing is carried out at the expense of the pumping unit in the room of the pumping automatic firefighting system at the platform level of the station complex.

The initial data is given below:

- Height of placement of the dictating sprinkler - $5 \mathrm{~m}$;

- Irrigation intensity of the protected area -0.180 $\mathrm{l} /\left(\mathrm{s} * \mathrm{~m}^{2}\right)$;

- Standard consumption (not less than) - 45 l/s;

- The minimum area of the sprinkler automatic firefighting system is $120 \mathrm{~m}^{2}$;

- The performance factor of the sprinkler $-0,71$;

- Area protected by a single sprinkler with the required intensity $-12 \mathrm{~m}^{2}$;

- Pressure of the dictating sprinkler - 0.5 MPa;

- The height of the section control unit is 1.5 meters;

- The estimated standard consumption of the section is $45 \mathrm{l} / \mathrm{s}$.

The pipeline in the protected area was divided into 9 sections. Each section between two sprinklers is 4.5 meters long. The length of the supply pipeline is defined as 390 meters. The type of pipeline is circular.

To provide fire extinguishing of areas of sedimentation of rolling stock with a fire extinguishing agent, a pumping unit was selected with two pumps connected in series and one backup.

The maximum water consumption per section, according to the calculation results, is $46.158 \mathrm{l} / \mathrm{s}$.

The maximum pressure on the section is $0.804 \mathrm{MPa}$.
The supply pipeline from the pump unit to the control unit is divided into two sections. The first section is 10 meters long-from the pump unit in the pump room of the automatic firefighting system to the exit outside the room. The second section is 425 meters long-from the premises of the pumping STATION located on the platform of the station complex to the protection zones of dead ends of night sediment of rolling stock. The pipeline type is a dead end.

Based on the calculation results, the following parameters of fire pumps that should be used in the pump unit are determined: water

Consumption - $46.158 \mathrm{l} / \mathrm{s}\left(166.168 \mathrm{~m}^{3} / \mathrm{h}\right)$;

Pressure - 1,399 MPa (139,904 meters of water column).

After completing the hydraulic calculation of the designed general-purpose fire extinguishing system, you should proceed directly to the selection of the most suitable system for operation in the conditions of metro dead ends based on the results of the calculations.

\subsection{Selecting the type of water fire extinguishing based on the results of calculations}

The system of water fire extinguishing with thinly sprayed high-pressure water requires a water flow rate of $34.2 \mathrm{l} / \mathrm{min}$ to ensure the protection of the object. The maximum calculated flow rate with simultaneous operation of 10 sprinklers on an estimated area of 120 $\mathrm{m} 2$ is equal to $342.0 \mathrm{l} / \mathrm{min}$. Taking into account the flow rate that is required for the operation of the drencher curtain $(171.0 \mathrm{l} / \mathrm{min})$, the total maximum flow rate is $513.0 \mathrm{l} / \mathrm{min}$

To ensure extinguishing during operation of a general-purpose water fire extinguishing system,a water flow rate of $5-5.5 \mathrm{l} / \mathrm{s}(300-330 \mathrm{l} / \mathrm{min})$ is required on sprinklers. The total water consumption of the Generalpurpose system will be 46.158 l/s (2769.48 l/min).

Therefore, it is concluded that the fire extinguishing system is more economical in terms of the consumption of fire extinguishing agent (water), as opposed to a lowpressure system. For the required water reserves, a comparison is made in the work below.

Considering the designed systems by pipe diameters, it is logical to conclude that in a low-pressure system, pipes of a larger diameter are used than in a highpressure thin-spray water system.

Namely, for a low-pressure system-pipes with a diameter of $100 \mathrm{~mm}$ in the section from the pump unit to the control units and pipes with a diameter of $78 \mathrm{~mm}$ in the sections of the supply pipeline.

System the water mist high pressure is applied, the pipe diameter of $38 \mathrm{~mm}$ on the plots from the pumping unit to control nodes and on sections of the supply line, pipe diameter $12 \mathrm{~mm}$ on carts to dispensers.

The linear meter of the DN78 pipe used in the lowpressure system has a mass of $7.8 \mathrm{~kg}$. The running meter of the DN100 pipe is $9.7 \mathrm{~kg}$.

Consequently, on the total mass mounted for the needs of fire communications, with the exception of the weight of the pumping unit and the sprinklers, we can 
conclude that the mass of a low pressure system will be (given the first two sections 10 and $425 \mathrm{~m}$, respectively, 9 sections of the supply line with a length of 4.5 meters each and a section from the management node to the design area 390 meters) - 32160,5 kg.

The linear meter of the DN12 pipe made of corrosion-resistant steel has a mass of $0.27 \mathrm{~kg}$. Linear meter of DN38 pipe made of corrosion-resistant steel $2.62 \mathrm{~kg}$.

Consider the total mass of the designed fire extinguishing system with high-pressure water spray. Taking into account sections equal to 0.5 meters with a pipe diameter of DN12 and other sections with a pipe diameter of DN38 with a total length of 839 meters (also excluding the mass of the pump unit and sprayers), the total mass of installed communications will be 19354.8 kg.

Having studied the cost of steel electric-welded pipes for general-purpose fire extinguishing systems, it should be concluded that the price of one meter of this pipe with diameters DN78 is approximately 350 rubles. One meter of electric-welded pipe with a diameter of DN100 will cost about 390 rubles.

The cost of one meter of stainless steel pipe made of steel grade $12 \mathrm{X} 18 \mathrm{~N} 10 \mathrm{~T}$ and a diameter of DN38 is approximately 1400 rubles. The cost of one meter of such a pipe with a diameter of DN12 is 260 rubles.

This leads to the conclusion that the total cost of pipeline communications for the installation of the designed low-pressure fire extinguishing system will be approximately 1421150 rubles.

The total cost of purchasing a pipeline for installing a fire extinguishing system with high-pressure water spray will be about 10377440 rubles.

Let's move on to comparing the designed systems with respect to the required supply of fire extinguishing agent to ensure extinguishing.

For a general-purpose system, based on the results of hydraulic calculations, a water flow rate of $46.158 \mathrm{l} / \mathrm{s}$ or $2769.48 \mathrm{l} / \mathrm{min}$ is required. Taking into account the fact that according to the standards given in this work, it is necessary to ensure extinguishing within 60 minutes, it should be concluded that the total amount of water for the general purpose fire extinguishing system will be 166168.8 liters.

However, it is necessary to take into account the mandatory $10 \%$ supply of fire extinguishing agent. Therefore, the total amount of water required for this fire extinguishing system is 182785.68 liters. For example, the volume of a standard pool for the Olympic games and world Championships is 2500,000 liters of water, the configuration of which is 50 meters long, 25 meters wide and 2 meters deep. To store the volume of water required for the fire extinguishing system in question, a tank 10 meters long, 10 meters wide and 2 meters high would be required.

This is quite a large volume, especially for metro facilities, the majority of which are located underground. It is simply not possible to place such a large reservoir within the space-planning solutions of the metro object. The only solution that can be taken to provide a fire extinguishing system with a fire extinguishing agent is to interact with the city water utility and request the necessary amount of water from them. However, when designing it is necessary to take into account the fact that the water utility does not always enter into a contract for the supply of water for the needs of fire extinguishing various objects.

Let's move on to the assessment of the necessary supply of fire extinguishing agent to ensure extinguishing by a high-pressure fire extinguishing system with thinly sprayed water.

Based on the calculation results, it is necessary to provide a flow rate of $513 \mathrm{l} / \mathrm{min}$. This number already includes a $10 \%$ supply of fire extinguishing agent. Also, taking into account the condition of fire extinguishing within 60 minutes, 30780 liters of water will be required. This volume of water required a much smaller reservoir. Approximately 5 meters long, 4 meters wide and only 1.5 meters high. In principle, such a water tank, if divided into several separate vessels, can fit even in the pump room of the automatic firefighting system, given that according to the standards this room should be at least $60 \mathrm{~m} 2$. In the case of a city water utility, it is much easier to allocate and provide such a volume of water than the required volume for a general - purpose system.

\section{Discussion}

The results of comparing the hydraulic calculations of two different fire extinguishing systems are presented below. According to the consumption of fire extinguishing agent and total water supply, the fire extinguishing system with thinly sprayed high-pressure water has an advantage over the other one.

Based on the diameter and weight of the linear meter of pipes, it is concluded that the total mass of communications and the mass of individual elements is significantly lower for a fire extinguishing system with high-pressure water in contrast to a general-purpose system.

However, despite the advantage in weight, the highpressure water spray system is much inferior in terms of cost. However, when designing a fire extinguishing system for a metro facility, the emphasis should be on operational efficiency rather than costs. That is why the choice is made in the favor of the high-pressure water spray system and, thus, a fire extinguishing system to ensure fire safety of dead ends of rolling stock sludge has to include high-pressure water spraying.

\section{References}

1. P. Zhu, W. Wei, J. Mei, J. Tu, R. Ding, Procedia $\begin{array}{lll}\text { Engineering, 205, } & \text { 87-94 } \\ \text { https://doi.org/10.1016/j.proeng.2017.09.938 }\end{array}$

2. T. Chen, S.Y. Zhang, L.Z. Zhao, et al, IOP Conference Series: Earth and Environmental Science, 69, 012179 (2017)

3. J. Yang, J. Liang, Q.-Z. He, Procedia Engineering, 211, 897-900 https://doi.org/10.1016/j.proeng.2017.12.089 
4. Y. Zhu, Y. Wang, X. Zhou, IOP Conference Series: Materials Science and Engineering, 423, 012019 (2018)

5. E.Y.Y. Chan, et al, International Journal of Environmental Research and Public Health, 16(2), 228 (2019) https://doi.org/10.3390/ijerph16020228

6. S. Moriyama, et al, Fire Safety Science, 8, 14611472 (2005) doi:10.3801/IAFSS.FSS.8-1461

7. Z. Wang, et al, Procedia Engineering, 84, 595-602 (2014)

8. V. Maslak, et al, Procedia Engineering, 165, 214223 (2016)

9. D. Gabay, Tun. And Und. Sp. Tech., 17(2), 139-143 (2002) https://doi.org/10.1016/S0886-7798(02)00016-0

10. R. Gao, A. Li, Y. Zhang, N. Luo, Saf. Sc., 80, 94104 (2015) https://doi.org/10.1016/j.ssci.2015.07.015

11. L. J. Hong, C. J. Liu, Chin., Jour. of Und. Sp. and Eng., 1(1), 149-154 (2005)

12. M. Gravit, A. Vaititckii, A. Shpakova, Procedia Engineering, 165, 1667-1672 (2016).

13. W.K. Chow, International Journal on Architectural Science, 5(2), 35-42 (2004)

14. J. Mao, et al, Journal of the China railway Society, 6 (2010)

15. R.E. Shaltout, M.A. Ismail, Sustainable Rail Transport. Springer, Cham., 209-228 (2020) https://doi.org/10.1007/978-3-030-19519-9_7

16. Subways. The updated edition of SNiP 32-02-2003, (SP 120.13330.2012, with Amendments No. 1-4)

17. Systems of fire protection. Automatic fireextinguishing and alarm systems. Designing and regulations rules, (SP 5.13130.2009, with Change N 1)

18. Fire engineering. Classification of fires (GOST 27331-87)

19. Rules for arrangement of electrical installations (PUE 7th edition)

20. Means for guarding. Fire and guarding fire signalization. Type, basic parameters and dimensions (GOST 26342-84, with Changes N 1,2)

21. Automatic fire extinguishing system with highpressure spray water "ALFA-FOG". Design recommendations (STO-20161283-001-2017) 